Journal of Zhejiang University-SCIENCE B (Biomedicine \& Biotechnology) ISSN 1673-1581 (Print); ISSN 1862-1783 (Online)

www.zju.edu.cn/jzus; www.springerlink.com

E-mail: jzus@zju.edu.cn

\title{
Correspondence:
}

\section{A case report on indirect transmission of human rabies}

Jian-yong ZHU, Jian PAN, Yuan-qiang $\mathrm{LU}^{\dagger+}$

(Department of Emergency Medicine, the First Affiliated Hospital, School of Medicine, Zhejiang University, Hangzhou 310003, China)

†E-mail: luyuanqiang609@163.com

doi:10.1631/jzus.B1500109

At present, virus infection is still a common threat to public health in developing countries (Liu et al., 2013; Mao et al., 2013; Zhang and Wang, 2014) Human rabies remains a matter of great global concern with a case-fatality of almost $100 \%$ (Willoughby et al., 2005; Takayama, 2008). The rabies virus belongs to the neurotropic type of virus of the Lyssavirus genus, and the disease presents as a deteriorating encephalomyelitis and is endemic throughout much of the world, particularly in Africa and Asia (Fooks et al., 2014). Previous data have shown that, globally, approximately 59000 human deaths are caused by rabies per year (Hampson et al., 2011). Fortunately, human rabies can be treated through the timely administration of post-exposure prophylaxis (PEP). These days immunization using the rabies vaccine has become standard practice for individuals who have suffered bites or scratches from an animal, or who have been exposed to the body fluids of an infected animal (Willoughby et al., 2005; Johnson et al., 2014). However, we have recently encountered a case of human rabies which arose through a rare transmission method, and we believe that lessons can and should be learnt from this incident.

On June 22, 2014, a middle-aged male worker suffered a laceration to his right thumb from a cutter knife. The wound was $1.5 \mathrm{~cm}$ in length, and was accompanied by minimal bleeding. Once cleaned, dis-

\footnotetext{
Corresponding author

(1) ORCID: Yuan-qiang LU, http://orcid.org/0000-0002-9057-4344

(c) Zhejiang University and Springer-Verlag Berlin Heidelberg 2015
}

infected, and sutured, the wound was dressed with gauze. As part of the treatment the patient received an administration of tetanus antitoxin. On July 6, the sutures were removed, and it was observed that the wound was healing well and subsequently redressed with gauze. On July 7 , a relative of the man was bitten on the right calf by a stray dog at a highway service station. When he assisted his relative, the man's gauze was contaminated with the relative's blood. The gauze was immediately discarded, but he did not seek further medical attention or receive a rabies vaccination. On Sept. 1, he began to experience nighttime agitation and sleep disturbance. On Sept. 9, he suffered from right upper extremity parasthesia in the form of crawling and stinging sensations. On Sept. 10, he experienced more severe symptoms including photophobia, hydrophobia, anemophobia, pharyngeal muscle spasms, excessive sweating, salivation, chest tightness, irritability, and delirium. He was transferred to our hospital and rabies was suspected based on clinical presentation. The patient was isolated in a quiet single room and advised to avoid light and stimulation; sedation was also provided. Saliva samples of the patient were collected and tested by the State Key Lab of Diagnosis and Treatment of Infectious Diseases (Hangzhou, China), and a nested reverse transcription-polymerase chain reaction (RTPCR) confirmed the presence of rabies virus RNA (Fig. 1). The reverse transcription-polymerase chain reaction (RT-PCR) kit for the detection of rabies virus RNA was purchased from TaKaRa Biotechnology Co., Ltd. (Dalian, China). The patient markedly deteriorated after admission, and experienced lapses in consciousness and convulsions. At 1:00 p.m. on Sept. 11 , he suffered cardiac and respiratory arrest, and then died after attempts at resuscitation proved unsuccessful. In contrast, the relative who was bitten by the rabid dog received timely inoculation with the rabies vaccine and suffered no complications. 


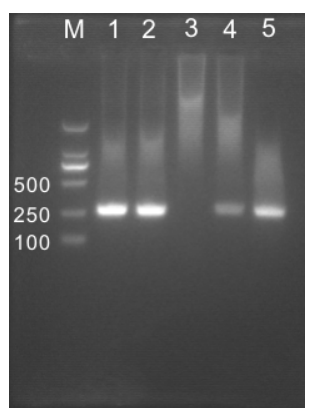

Fig. 1 Agarose gel electrophoresis of nested RT-PCR identifying the RNA of rabies virus at the target fragment of $255 \mathrm{bp}$

M: DL2000 marker; 1-5: saliva samples

At present, most developed countries have effectively eliminated rabies from their domestic dog populations (Coleman et al., 2004). However, as a developing country, human rabies remains a significant health risk in some areas in China. The poorest countries or regions are most vulnerable to the threat of a rabies epidemic, as the administration of domestic dog vaccinations is not widespread or consistent (Hampson et al., 2015).

Generally speaking, human rabies has unique clinical manifestations that are easily distinguished from other conditions, and death is usually inevitable following clinical onset. Information about whether or not the deceased patient had a prior history of animal bites or exposure to animal body fluids is usually pivotal in directing the diagnosis away from rabies. However, the aforementioned case was unusual because of the method of virus transmission, namely that it is possible that the rabies virus was indirectly transmitted from one person to another through the exposure of damaged skin to salivacontaminated blood from an individual bitten by a rabid dog.

Thus, a key lesson which the current case reveals is that in instances where broken skin or mucous membranes have been exposed to salivacontaminated blood of an individual who has been bitten by an animal, he/she should receive timely wound management and immediate administration of rabies vaccine and/or human rabies immunoglobulin.

\section{Compliance with ethics guidelines}

Jian-yong ZHU, Jian PAN, and Yuan-qiang LU declare that they have no conflict of interest.

All procedures followed were in accordance with the ethical standards of the responsible committee on human experimentation (institutional and national) and with the Hel- sinki Declaration of 1975, as revised in 2008 (5). Informed consent was obtained from all patients for being included in the study.

\section{References}

Coleman, P.G., Fèvre, E.M., Cleaveland, S., 2004. Estimating the public health impact of rabies. Emerg. Infect. Dis., 10(1):140-142. [doi:10.3201/eid1001.020774]

Fooks, A.R., Banyard, A.C., Horton, D.L., et al., 2014. Current status of rabies and prospects for elimination. Lancet, 384(9951):1389-1399. [doi:10.1016/S0140-6736(13)627 07-5]

Hampson, K., Cleaveland, S., Briggs, D., 2011. Evaluation of cost-effective strategies for rabies post-exposure vaccination in low-income countries. PLoS Negl. Trop. Dis., 5(3):e982. [doi:10.1371/journal.pntd.0000982]

Hampson, K., Coudeville, L., Lembo, T., et al., 2015. Estimating the global burden of endemic canine rabies. PLoS Negl. Trop. Dis., 9(4):e0003709. [doi:10.1371/journal. pntd.0003709]

Johnson, N., Aréchiga-Ceballos, N., Aguilar-Setien, A., 2014. Vampire bat rabies: ecology, epidemiology and control. Viruses, 6(5):1911-1928. [doi:10.3390/v6051911]

Liu, Q., Su, X.J., Yu, Y., et al., 2013. Correlation between virus persistent infection and cardic function in patients with dilated cardiomyopathy. J. Zhejiang Univ.-Sci. B (Biomed. \& Biotechnol.), 14(8):749-753. [doi:10.1631/ jzus.BQICC708]

Mao, W.L., Shi, X.P., Lou, Y.F., et al., 2013. The association between circulating oestradiol levels and severity of liver disease in males with hepatitis B virus infection. Liver Int., 33(8):1211-1217. [doi:10.1111/liv.12160]

Takayama, N., 2008. Rabies: a preventable but incurable disease. J. Infect. Chemother., 14(1):8-14. [doi:10.1007/ s10156-007-0573-0]

Willoughby, R.E.Jr., Tieves, K.S., Hoffman, G.M., et al., 2005. Survival after treatment of rabies with induction of coma. N. Engl. J. Med., 352(24):2508-2514. [doi:10.1056/ NEJMoa050382]

Zhang, L., Wang, H., 2014. Forty years of the war against Ebola. J. Zhejiang Univ.-Sci. B (Biomed. \& Biotechnol.), 15(9):761-765. [doi:10.1631/jzus.B1400222]

\section{中文概要}

\section{题 目: 一例罕见的间接传播人狂犬病}

概 要: 本文回顾性报告了一例较为罕见的间接传播人狂 犬病患者的得病经过和救治过程, 对其中的特殊 之处进行分析和思考。本病例提供的一线临床实 践资料, 有助于提高对该疾病的认识以及制定更 为科学、合理的狂犬病防治方案。该狂犬病患者 无动物咬伤或接触动物体液等相关病史, 而是通 过其有少许皮损的拇指接触到被狗咬伤者的血 液（可能被狗唾液污染）而感染狂犬病病毒, 即 间接的接触传播。因而, 对于这类患者, 临床上 也应及时接种狂犬病疫苗或给予抗狂犬病免疫 球蛋白。

关键词: 狂犬病; 传染病; 病毒; 预防接种 